\title{
The behavior over time of postnatal depression symptomatology and its early detection via the Edinburgh Postnatal Depression Scale: An Italian longitudinal study
}

\author{
M. Caterina Cattaneo ${ }^{1}$, , Sara Roveraro ${ }^{1}$, Valentina Chiorino ${ }^{1}$, Elena A. Macchi ${ }^{1}$, Roberta Salerno ${ }^{1}$, \\ Monica Gatti ${ }^{2}$, Laura Arcaro ${ }^{1}$, Francesco Barretta ${ }^{3}$, Camilla B. Fontana ${ }^{4}$, Lorenzo Colombo Md ${ }^{4}$, \\ Piero G. Rossi Md ${ }^{5}$, Prof. Fabio Mosca ${ }^{4}$ \\ ${ }^{1}$ Perinatal Psychology Unit, Consultorio Familiare Accreditato ASL “Genitori Oggi”-CAV Mangiagalli, Milan, Italy \\ ${ }^{2}$ Department of Psychology, Università Cattolica del Sacro Cuore - Milan, Italy \\ ${ }^{3}$ Departments of Clinical Sciences and Community Health, University of Milan. Epidemiology Unit, Department of Preventive \\ Medicine, Fondazione IRCCS Cà Granda- Ospedale Maggiore Policlinico, Milan, Italy \\ ${ }^{4}$ NICU, Fondazione IRCCS Cà Granda - Ospedale Maggiore Policlinico, Università degli Studi di Milano, Milan, Italy \\ ${ }^{5}$ Department of Obstetrics and Gynecology, Fondazione IRCCS Cà Granda- Ospedale Maggiore Policlinico, Milan, Italy \\ *Corresponding author E-mail: ricerca.mangiagalli@genitorioggi.it
}

\begin{abstract}
Background: Becoming a mother for the first time is a significant developmental transition and postpartum mood disorders represents the most frequent form of maternal morbidity following delivery.

Objective: To investigate the ability of Edinburgh Postnatal Depression Scale (EPDS) to detect, in the first days postpartum, mothers at risk of developing depressive symptomatology over time.

Results: The percentage of mothers with an EPDS score $\geq 10$ decreases over time: $23.77 \%$ at $2 / 5$ days postpartum, $15.57 \%$ at 2 months and $9.02 \%$ at 6 months after delivery. Among mothers with a depressive symptomatology after $2 / 5$ days postpartum, $41.38 \%$ maintained an EPDS score $\geq 10$ at 2 months too, while $20.69 \%$ of them manifested depressive symptoms at 6 months as well. Both correlation and linear regression showed a significant association between EPDS scores in all three administrations of the study but EPDS score at $2 / 5$ days postpartum is more associated and predictive to maternal mood at two months than at six months postpartum.

Method: A longitudinal study was conducting on 122 primiparous mothers who filled out EPDS and a General Information Questionnaire at $2 / 5$ days postpartum, at $2 / 3$ and $6 / 7$ months after delivery. Women with high EPDS scores $(\geq 10)$ were compared to those who had scored $<10$ in all the three steps and longitudinal analysis were conducted.

Conclusion: Implementing EPDS in the first week postpartum allows identifying women at high risk to maintain depressive symptoms over time. These findings could be useful for health care interventions after delivery and for researchers involved in the study of transcultural aspects of postnatal depression.
\end{abstract}

Keywords: EPDS; Maternal Depressive Symptoms, Postnatal Depression; Postpartum Depression Symptomatology; Screening.

\section{Introduction}

Childbirth represents for women a time of great vulnerability to become mentally unwell and postpartum mood disorders representing the most frequent form of maternal morbidity following delivery (Stocky \& Linch, 2000; Dennis, 2004). These affective disorders range in severity from the early maternity blues to postpartum psychosis (Evins \& Theofrastous, 1997). Along this spectrum, postnatal depression is the most frequent with a prevalence that ranges from $10 \%$ to more than $20 \%$ of women affected, and depends on the assessment method used the timing of the assessment, and the cultural characteristics of the population (Burt \& Stein 2002). During the first year after childbirth, women globally manifest mild disorders mood and moderate psychological and somatic symptoms (Grussu et al., 2001). In particular, literature data report a difficult transition for first time parents: becoming a mother is significant developmental transition that can cause anxiety with the change of role from being a non- parental and responsible only for one's self to being responsible for the care of the new baby (Leahy-Warren et al, 2011). Specifically primiparous mothers presenting higher anxiety and depression than second time mothers during pregnancy and the post-partum (Hung, 2004; Dørheim et al., 2009; Giakoumaki et al., 2009; Gameiro et al., 2009). However, researches present controversial results regarding depression symptoms in first and second time parents, in fact some studies report lower depression levels in primaparous women compared to second time mothers in the post-partum period (Skari et al; 2002). Therefore, this research topic needs to be more investigated.

Literature shows that postnatal depression has a three-fold on mother's health, on the couple and on the cognitive and psychoaffective development of the baby impact (Cox \& Holden, 2003; Jardri et al., 2006). Women who have suffered of postpartum depression are twice as likely to experience future episodes of depression over a 5 -year period (Cooper \& Murray, 1995). As a matter of fact, MacMahon et al. (2005) found that $60 \%$ of women identified as being depressed at 4 months are still 
clinically depressed 1 year after delivery. In the development of postpartum depression, the predictive power of maternal mood during the immediate postpartum period has consistently been reported (Hannan et al, 1992; Dennis, 2004; Teissedre \& Chabrol, 2004). Hannan et al. (1992) noted a significant correlation between the mother's affective state on the fifth day postpartum and at 6 weeks both measured using the Edinburgh Postnatal Depressive Scale (EPDS).

EPDS was developed to help screen for postpartum depression (Cox et al., 1987) and it could be used in practice as a mass screening tool for postpartum depression in the maternity unit by non - psychiatric staff (Jardri et al., 2006).

Dennis (2004), using EPDS, demonstrated a strong relationship between maternal mood at 1,4 and 8 weeks postpartum. Teissendre and Chabrol (2004) also assessed the fidelity with time of EPDS, using a large number of women, on the third day postpartum and between 4 and 6 weeks postpartum. Recently, Jardri et al. (2006) confirmed that it is valid to use EPDS between day three and day five postpartum and that it was predictive of a depressive state at 8 weeks postpartum. Therefore, the saliency of maternal mood within the first 2 weeks postpartum as a predictor of postnatal depression has been further substantiated.

In the past ten years Italian studies used the EPDS to assess the depression symptomatology during pregnancy and after delivery, often in combination with other instruments (Monti et al., 2006; Grussu \& Quatraro, 2009), but only few studies have specifically assessed the stability of maternal mood or the concordance between EPDS scores in the immediate postpartum period and mother's EPDS scores in the long period. For example Agostini et al., (2005) explored the postpartum depressive symptomatology after 3, 9 and 18 months after the childbirth in 53 mothers recruited at their third trimester of pregnancy. The results was that the percentage of women that have a postpartum depressive symptomatology decreases over time: $37.7 \%$ at 3 months, $35.8 \%$ at 9 months and $24.5 \%$ at 18 months showed a EPDS scores above cut-off. Furthermore regression analysis showed that scores of EPDS (cut-off score 8/9) at 18 month were associated to previous scores, particularly to 9 months scores.

Despite these attempts, in national and international researches still remain the tendencies to focus studies on the early beginning of the appearance of postpartum symptomatology depression rather than the stability of the same in periods distant from childbirth.

So the purpose of this study was to fill up this lack evaluating the capacity of the Italian version of the EPDS (Benvenuti et al. 1999), implemented in the very first days postpartum, to detect women who will suffer from postnatal depression symptomatology, during the perinatal period.

In particular, we want to assessed the stability of maternal mood and the concordance between EPDS scores, specifically in primiparous mothers.

Furthermore we want to verify the effectiveness of EPDS score to identify mothers at risk to develop depressive symptoms during the first six months postpartum.

Three sensible steps of the perinatal period were considered:

Step 1: 2/5 days postpartum because the childbirth represents a time of high vulnerability for the mothers and mood disorders are frequent after delivery (Stocky \& Lynch, 2000).

Step 2: Two months postpartum, when the baby blues always decrease completely. This is a very sensible period for the interactions between mother and child: baby is able of activating a playful communication in the waking state and it needs a responsive mother who tends to reflect the mimicry of the newborn and able to comprehend the mental state of her child (Stern, 1985; Trevarthen \& Aitken, 2001).

Step 3: Six months after delivery when literature data report to be the most sensible period for post natal depression (Monti \& Agostini, 2006).

\section{Methods}

\subsection{Partecipants}

122 Italian women who gave birth in the Mother and Infant Department in the Fondazione Ca' Granda, IRCCS Ospedale Maggiore Policlinico, Milan, Italy agreed to participate voluntarily at this study.

Inclusion criteria for woman were to be primiparous and Italian by birth, residence and culture, having at least 18 years old and with a partner.

These criteria were chosen to minimize some psychosocial risk factors like lack of support from partner, being immigrants and poor social support. Indeed in literature these conditions seem to report persistent and higher symptoms of depression in mothers. (Brugha et al, 2000; Danaci et al, 2002; Dennis et al, 2004; Dennis \& Ross, 2006).

This sample is part of a more larger longitudinal research in which were recruited couples of mothers and fathers at their first child, it comprehended the administration of several tests to explore not only the postnatal depression symptomatology but also the clinic depression and the parental stress.

\subsection{Assessment}

\subsubsection{General information questionnaire}

Data on social and demographic characteristics and about obstetric and psychological variables were collected 2-5 days postpartum, with a General Information Questionnaire specifically realized for this study from the researchers. The questionnaire included items on maternal age, occupation, education, people the mother lives with, type of delivery and infant-feeding method at the discharge. We also investigated variables as infant-feeding method, mother's own experience of breastfeeding, desire to breastfeed before and after delivery, desire for offspring, mother's perception of delivery, and mother's perception of their own body during pregnancy and after childbirth, previous history of anxiety or depression and type of treatment used for that. Nonetheless for the propose of this study these values will be not specifically analyzed.

\subsubsection{Edinburgh postnatal depression scale (EPDS, Cox et al., 1987)}

It's a 10-item self-report questionnaire specifically designed to assess postpartum depression symptomatology in women who have just given birth. The scale has a documented reliability and validity in multiple languages (Affonso et al., 2000).

Item 1 and 2 assess anhedonia; item 3 self-blame; item 4 anxiety; item 5 fear or panic; item 6 inability to cope; item 7 difficulty sleeping; item 8 sadness; item 9 tearfulness; and item 10 self-harm ideas. Responses are scored 0, 1, 2 and 3 increasing according to the severity of symptom. The total score is calculated by adding the scores for each of the 10 items. The score can range from 0 to 30 .

In this study, women who scored more than 9 on the EPDS were defined exhibiting postpartum depressive symptomatology. This cut-off point is recommended to increase the sensibility for population-based screening (Murray \& Carothers, 1990) and for the daily use from primary care workers (Cox et al, 1987). Furthermore, in the Italian validation of EPDS by Benvenuti et al. (1999), a cut off $9 / 10$ had a good sensitivity of $83.3 \%$ and good specificity of $89.5 \%$.

\subsection{Procedure}

This study was conducted in Milan, in north-western Italy by the equipe of psychologists and psychotherapists of the Family Service, Consultorio Familiare "Genitori Oggi", this research has been done in collaboration with the Mother and Infant Department 
of Fondazione $\mathrm{Ca}$ ' Granda, IRCCS Ospedale Maggiore Policlinico.

Between the second and the fifth days postpartum, during the hospitalization, the women were asked to complete the Italian version of the EPDS (Benvenuti et al. 1999) and to fill out the general information questionnaire. Individual written informed consent was obtained for all women.

In additions, the EPDS was mailed to all participants at $2 / 3$ and 6/7 months postpartum. Reminder telephone calls were provided to mothers who did not return their questionnaire within 2 weeks of mailing.

Every subject with EPDS score over cut-off and with affirmative answer at item number 10 "suicidal thoughts" was called for a psychological interview.

The institutional review board of the Consultorio Familiare Unit approved this retrospective study.

\subsection{Statistical analysis}

Study group characteristics and EPDS tests results were described through usual descriptive statistics (mean, SD., absolute and relative frequencies, median and IQR).

To assess the association between test results we perform Fisher's Exact Tests. P-value lower than 0.05 was considered significant. Also, strength and direction of the associations were evaluated using Pearson Correlation Coefficient and described by means of the graphical results of Simple Linear Regression models.

All the analysis were implemented with the program SAS 9.2, SAS Institute Inc.,Cary, NC.

\section{Results}

\subsection{Sample characteristics}

122 primiparous mothers agreed to participate to the study, and complete EPDS questionnaire at 2/5 days from the delivery and at 2-3 months postpartum, while only 119 women (97.5\%) completed all three steps of the study.

The mean age of the mothers who participated in this study was $34.43(\mathrm{SD}=4.06)$ with a range of 22 and 44 years. Characteristics of mothers collected by the General Information Questionnaire are described in the Table 1.

\subsection{EPDS results}

The mean of EPDS scores after 2/5 days after delivery, at two and six months postpartum were $6.20(\mathrm{SD}=4.70) ; 4.94(\mathrm{SD}=4.36)$; $4.04(\mathrm{SD}=4.06)$.

From the analysis emerged that $23.77 \%(\mathrm{~N}=29)$ of mothers at $2 / 5$ days postpartum had a EPDS score $\geq 10$, this percentage decreases to $15.57 \%(\mathrm{~N}=19)$ at 2 months and $9.02 \%(\mathrm{~N}=11)$ at 6 months postpartum.

For mothers with EPDS scores $\geq 10$ the mean scores were 13.03 $(\mathrm{SD}=2.29)$ in the first step, $13.05(\mathrm{SD}=2.17)$ in the second step and $13.55(\mathrm{SD}=3.39)$ at 6 months postpartum. The mean of EPDS scores in women without a depressive symptomatology $($ EPDS $<10)$ in the three times of administrations were 4.08 ( $\mathrm{SD}=$ $2.86), 3.45$ ( $\mathrm{SD}=2.69$ ) and 3.07 ( $\mathrm{SD}=2.63$ ), respectively.

The percentages of mothers expressing any self-harming ideas were $0.82 \%(\mathrm{~N}=1)$ at $2 / 5$ days postpartum, $3.36 \%(\mathrm{~N}=4)$ at 2 months and $6.09 \%(\mathrm{~N}=7)$ at six months.

All these data, with also median score and IQR are reported in Table 2 .
Table 1: Characteristics of First Time Mothers

Mothers

$(\mathrm{N}=122)$

Age, mean \pm SD

$34.43 \pm 4.06$

Level of education, $\mathrm{N}(\%)$

Intermediate School $6(4.9)$

High School $43(35.2)$

University $71(58.2)$

Missing 2 (1.6)

Work, $\mathrm{N}(\%)$

Freelancer $20(16.4)$

Manager $3(2.5)$

Employed/Teacher $\quad 89(73)$

Housewife $\quad 5(4.1)$

Worker $2(1.6)$

Merchant $1(1.8)$

Missing 2 (1.6)

Type of delivery, $\mathrm{N}(\%)$

Vaginal $64(52.5)$

Caesarian Section $\quad 58(47.5)$

Infant feeding methods at the discharge, $\mathrm{N}(\%)$

Breastfeeding

Mixed feeding $7(5.7)$

Missing $36(29.5)$

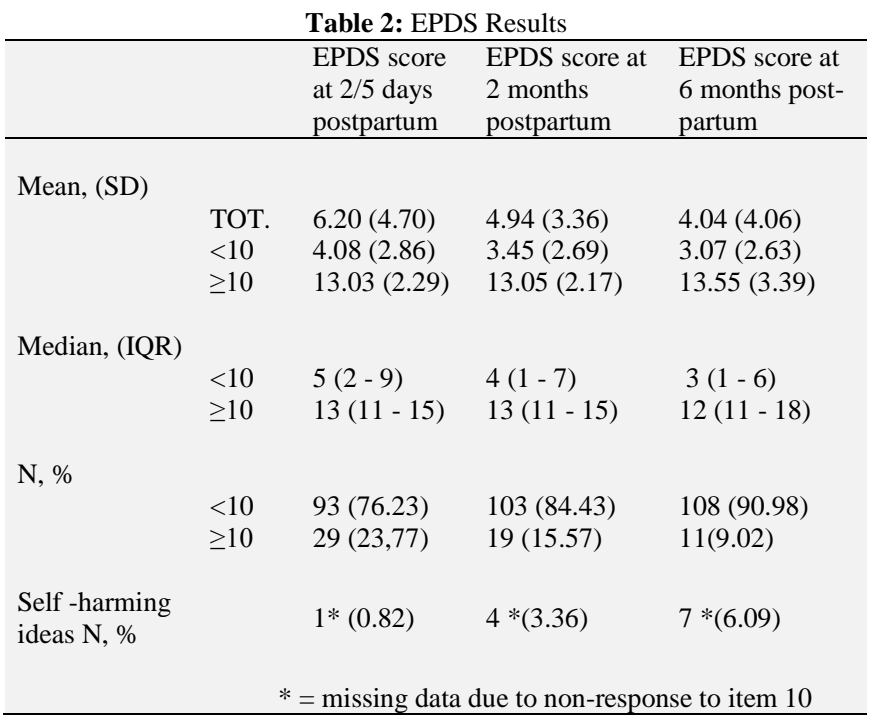

\subsection{Early EPDS test's prediction evaluation}

The EPDS capability to identify, already at 2/5 days postpartum those women who are at risk manifesting a depressive symptomatology during the first six months postpartum, was evaluated using the Fisher's Exact Tests.

We analyzed how many women maintained a depressive symptomatology (EPDS score $\geq 10$ ) and those who did not (EPDS $<10)$ during the first six months after delivery. 9.84\% (N $=12$ ) of mothers maintained an EPDS score $\geq 10$ both at $2 / 5$ days and at 2 months postpartum, while $5.04 \%(\mathrm{~N}=6)$ mothers with an EPDS score $\geq 10$ after $2 / 5$ days showed a depressive symptomatology after six months too.

Furthermore, $4.20 \%(\mathrm{~N}=5)$ of mothers showed a depressive mood (continued EPDS score $\geq 10$ ) at two months and at six months postpartum too.

Finally, only 4 women on 119 (3.36\%) maintained a depressive symptomatology in all three implementations of the test while $66.4 \%(\mathrm{~N}=79$ on 119) never presented depressive symptoms. Anyway, there is a strength association between the first two test results and the last one $(\mathrm{p}<0.05)$. In fact $33.33 \%(\mathrm{~N}=4)$ of the women depressed at the first two steps resulted depressed at six 
month as well, while only $4.82 \%(\mathrm{~N}=4)$ of never depressed new mothers appeared depressed at the end of the follow-up.

Our results proved a significant association among all three temporal steps: women with a depressive symptomatology (EPDS $\geq 10$ ) and those who did not (EPDS $<10)$ in the three administration of the test showed a temporal continuity in the scores (Table 3 ).

Table 3: Joint Distributions of Depressive Symptomatology (EPDS $\geq 10$ ) Between Test's Administrations

\begin{tabular}{|c|c|c|c|c|}
\hline & & $\begin{array}{l}\text { EPDS score at } \\
2 \text { months } \\
\text { postpartum } \\
<10\end{array}$ & $\begin{array}{l}\text { EPDS score at } 2 \\
\text { months postpar- } \\
\text { tum } \\
\geq 10\end{array}$ & $\begin{array}{l}\mathrm{p}- \\
\text { value }^{\mathrm{a}}\end{array}$ \\
\hline \multirow{2}{*}{$\begin{array}{l}\text { EPDS score at } 2 / 5 \\
\text { days postpartum, } \\
\mathrm{N}(\%)\end{array}$} & $<10$ & $86(70.49)$ & $7(5.74)$ & \\
\hline & $\geq 10$ & 17 (13.93) & $12(9.84)$ & $<0.01$ \\
\hline & & $\begin{array}{l}\text { EPDS score at } \\
6 \text { months } \\
\text { postpartum }\end{array}$ & $\begin{array}{l}\text { EPDS score at } 6 \\
\text { months postpar- } \\
\text { tum }\end{array}$ & $\begin{array}{l}\mathrm{p}- \\
\text { value }^{\mathrm{a}}\end{array}$ \\
\hline & & $<10$ & $\geq 10$ & \\
\hline \multirow{2}{*}{$\begin{array}{l}\text { EPDS score at } 2 / 5 \\
\text { days postpartum, } \\
\mathrm{N}(\%)\end{array}$} & $<10$ & 85 (71.43) & $5(4.20)$ & \\
\hline & $\geq 10$ & 23 (19.33) & $6(5.04)$ & $<0.05$ \\
\hline \multirow[t]{2}{*}{$\begin{array}{l}\text { EPDS score at } 2 \\
\text { months postpar- } \\
\text { tum, } \mathrm{N}(\%)\end{array}$} & $<10$ & 94 (78.99) & $6(5.04)$ & \\
\hline & $\geq 10$ & 14 (11.76) & $5(4.20)$ & $<0.05$ \\
\hline \multirow[t]{3}{*}{$\begin{array}{l}\text { Combined EPDS } \\
\text { score at } 2 / 5 \text { days } \\
\text { and at } 2 \text { months, } \mathrm{N} \\
\text { (Row \%) }\end{array}$} & $<10$ & 79 (95.18) & $4(4.82)$ & \\
\hline & $\begin{array}{l}\text { Mixed } \\
\text { results }\end{array}$ & $21(87.50)$ & $3(12.50)$ & \\
\hline & $\geq 10$ & 8 (66.67) & $4(33.33)$ & $<0.01$ \\
\hline
\end{tabular}

In consistent with these findings we used Pearson Correlation Coefficient to assess the stability of the maternal mood over time. The EPDS score in the first step presented a high positive correlation with EPDS score at the second step $(r=.509 ; \mathrm{p}<0.01)$ and with EPDS score at the third step $(r=.407 ; \mathrm{p}<0.01)$. Furthermore EPDS score at 2 months correlated positively with EPDS score at 6 months post-partum $(r=.448 ; \mathrm{p}<0.01)$.

In order to better show the predictive power of the EPDS at $2 / 5$ days post-partum and of EPDS at 2 moths postpartum the graphics rappresentations of Simple Linear Regression Models is reported Regression analysis showed that scores of EPDS were associated in all three steps of the administrations although the strength of the association decrees over time, relative graphics are presented: (Fig. $1 ; 2 ; 3$ )

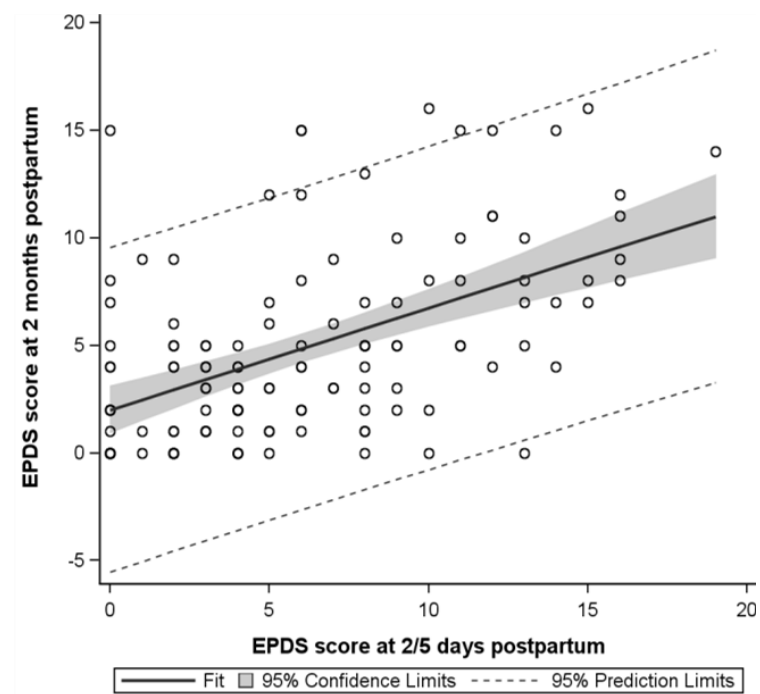

Fig. 1: Association between EPDS Scores at 2/5 Days Postpartum and at 2 Months after Delivery.

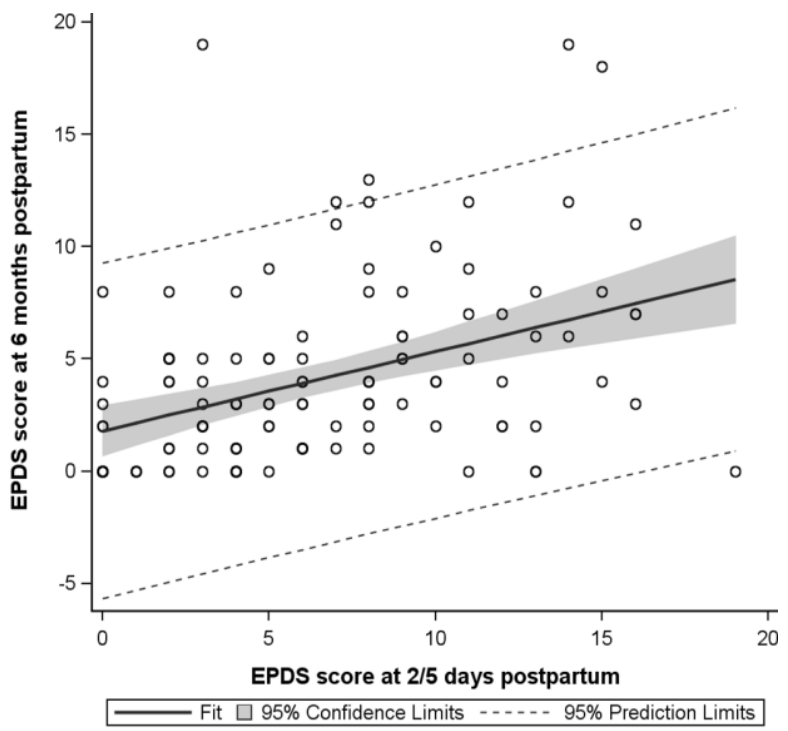

Fig. 2: Association between EPDS Scores at 2/5 Days Postpartum and At 6 Months after Delivery.

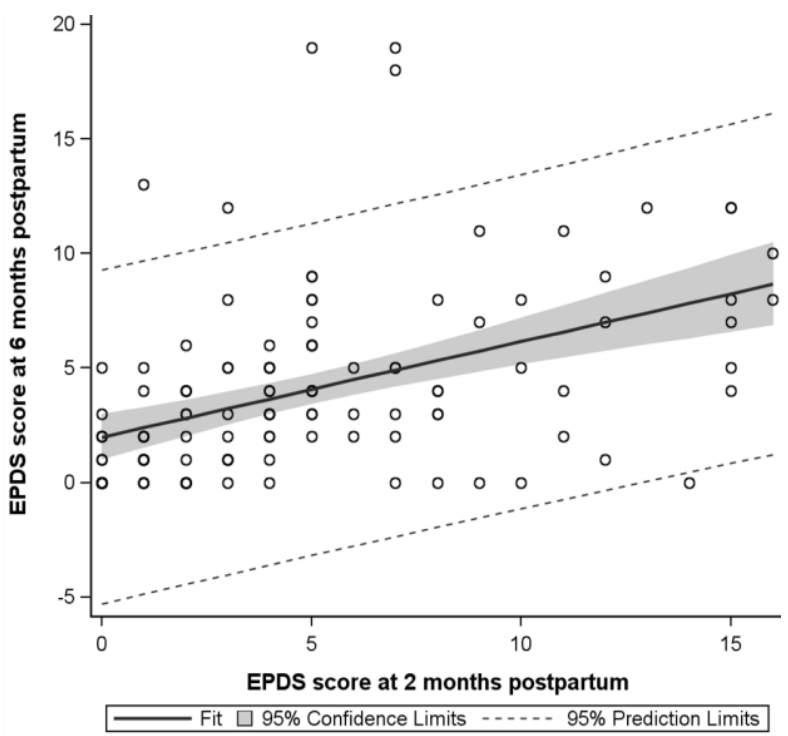

Fig. 3: Association between EPDS Scores at 2 Months Postpartum and at 6 Months after Delivery. 


\section{Discussion}

This study confirms that EPDS test, implemented in the very first days postpartum, is a valid instrument to screen the trend of maternal mood and so identify mothers at risk to develop depressive symptoms.

The prevalence rate of mothers of our study with depressive simptomatology (EPDS $\geq 10)$ decreases according with data reported by previous researches (Dennis, 2004; Agostini et al. 2005; Dennis \& Ross, 2006; Edhborg, 2008). In our study $23.8 \%$ of women reported a depressive symptomatology at $2 / 5$ days after delivery, similar to the rates reported by Dennis (2004) where $29.5 \%$ of mothers report an EPDS score $>9$ at 1 week postpartum and Edhborg (2008) who obtained that $24 \%$ of new mothers presented depressive symptoms 1 week after delivery (EPDS $\geq 10$ ). In contrast with our result Lilja et al., (2012) has founded, at 3 days postpartum, a lower percentage (14.3\%) of depressed new mothers (EPDS $\geq 10$ ), while at 10 days post-partum they revealed a percentage of symptomatic mothers $(22 \%)$ more in concordance with our results.

At the second administration of the test, at 2 months post-partum, $15.6 \%$ of women of our research reported an EPDS score $\geq 10$ These results findings consistent with others studies: for example Leahy -Warren (2011) observe that $13.2 \%$ of first time mothers present a post natal depression at 6 weeks postpartum (EPDS>11); Dennis and Ross (2006) reported that 20,3\% of mothers present a depressive mood at 8 weeks post-partum (EPDS >9) while Giardinelli et al. (2011), with an EPDS cut-off score $\geq 10$, revealed that $13.2 \%$ of mothers present depressive symptoms at 3 months postpartum.

After six months postpartum 9\% of our mothers showed an EPDS score $\geq 10$ and this decreasing of the percentage is substantially similar to other studies (Agostini et al., 2005; Lilja et al., 2012). Consistently with literature the highest prevalence of depressive symptoms occurs in the first 3 months and gradually falls over during the next years (Agostini et al., 2005; Banti et al., 2011).

The decrease reflects the trend of the percentages of the physiological postpartum where during the first months is necessary an adjustment to this new condition. If also we considered that women of this sample are primiparous, these scores could explain the difficult to become familiar with the new role of mother.

Considering that EPDS could also be a valuable instrument to measure "post-partum baby blues" (Edhborg, 2008), our data reports that 17 women on $29(58.62 \%)$, identified with depressive simptomatology after $2 / 5$ days from delivery, do not manifest a depressive mood after two months. So the primary cause of these false positive rates could be the high prevalence of "baby blues" that affects, as reported, up to the $75 \%$ of women during the first week postpartum (Nonacs \& Cohen, 1998; Edhborg, 2008). Furthermore the cut-off score (EPDS $\geq 10$ )chosen for this study identify depressive mood and not only clinical depression, probably if we had used a higher cut-off (i.e EPDS $\geq 12$ ) we would have included fewer false positive but with a sensitivity less adequate with the aim of screening of this research.

This transient mood disorder generally resolves within the first two weeks after delivery, so an EPDS score $\geq 10$ after two months postpartum probably indicates persistent depressive trend no more identifiable as "baby blues".

Results showed that among mothers with a depressive symptomatology after $2 / 5$ days postpartum, $41.38 \%(\mathrm{~N}=12)$ of them maintained an EPDS score $\geq 10$ at 2 months too, while only $20.69 \%$ of them $(\mathrm{N}=6)$ manifested depressive symptoms at 6 months as well. The significant difference between two groups of mothers indicates that there is continuity in the scores of the tests of the three steps.

Furthermore correlations confirms that there is a significant positive correlations between EPDS score at 2 day, 2 months and six months postpartum according with national (Grussu et al., 2001; Grussu \& Quatraro, 2009) and international studies (Hannan et al., 1992; Dennis, 2004; Teissèdre \& Chabrol, 2004).
Linear regressions show also strong associations between maternal moods in all the three steps considered in this study.

Although a significant association between EPDS scores in all 3 steps of the study was showed, the strength of the association decreases over time both with correlations and linear regressions consistent with others data in literature (Dennis; 2004; Teissèdre \& Chabrol, 2006)

Data report that EPDS score at $2 / 5$ days postpartum is more associated and predictive to maternal mood at two months than at six months postpartum. Indeed at this time the need of learning new skills related to infant care and the new parenting role may be stressful and one of the major causes of difficulties in those new mothers that had already a depressive mood after delivery.

At the same time EPDS score at two months postpartum is more associated to maternal mood at six months than EPDS score at 2/5 days after delivery.

Also in the Italian study of Agostini et al., (2005) regressions analysis showed that EPDS score, at 18 month postpartum, were more associated to 9 months score than to 3 months score.

These differences in temporal association could suppose that EPDS score is more able to better identify mothers that will develop psychological difficulties related to the delivery or to the new role of mothers while for women with depressive mood after six months postpartum probably attend other personal, social or structural variables.

These hypothesis could be confirmed by the increase of mothers ( 1 mother at 2/5 days after delivery to 7 mothers after six months postpartum) with an affirmative answer to the item number 10 , self -harm ideas, and by the increase of the mean scores of those mother with an EPDS total score of 10 or more.

\subsection{Limitations and future research}

Although the EPDS has established psychometric properties in screening for depression, diagnostic measure of depression was not considered in this step of analysis. Furthermore our sample considered only primiparous Italian mothers with a partner and better educated compared with women in the general population. Finally the method of administration of the tests by e-mail could be not guaranteed the accuracy of the setting of compilation.

For future researches we suggest to explore the influence of those risk factors which could make the screening of mothers at risk to develop a depressive symptomatology more accurately.

There is wide evidence in literature about the significant influence of psychosocial risk factors to predict depressive mood in women during postpartum period (Robertson et al., 2004; Leahy-Warren et al., 2011).

At the same time from our clinic experience, we noted some variables related to personal history of the mother which are very common in women manifesting depressive symptoms during the recovery in hospital after delivery. Difficult to breastfeed the baby, type of experience of breastfeeding in the family of origin, the perception of her body during pregnancy and after delivery or the description of the delivery too, could be predictive values of a depressive mood in the mothers during the first year of child.

So in future research, our aim is directed to study these specific woman's obstetric and personal variables to create a profile of new mothers at risk to maintain depressive symptoms and so structure an optimal screenings procedures easy to administered and with sensible markers.

\section{Conclusion}

In conclusion consistent with literature EPDS has been shown as a useful early screening tool with a cut-off of 9/10 (Dennis, 2004; Dennis \& Ross 2006; Agostini et al., 2005; Lilja et al., 2012). This test should be used routinely while mothers are still in hospital to early identify women at high risk to continue to exhibit depressive symptoms in particular at two months postpartum. 
This questionnaire could help the health professional to early detect mothers with a depressive mood and so activate a professional intervention already during the hospitalization after the delivery.

An operative indication could be makes midwives or doctors administer the test to advise accurately women with an EPDS score of 10 or more and then activate a psychological interview. Furthermore it would be useful administered the same test even after two months of birth especially in those mothers who have had an EPDS above cut-off at the first step to identify the presence of depressive trend in women.

\section{Acknowledgments}

The authors would like to thank the director of the Consultorio Familiare "Genitori Oggi" and CAV Mangiagalli of Milan Dr. Paola Bonzi, for her constant support and for believing in this project. The authors also especially acknowledge Mariangela Negri and Rosa Restieri, the midwives of the Department of Obstetrics and Gynecology and the nurses of Neonatology Unit of Fondazione IRCCS Cà Granda - Ospedale Maggiore Policlinico, Mangiagalli, Milan, for their availability and collaboration.

\section{References}

[1] Affonso DD, De AK, Horowitz JA \& Mayberry LL (2000) An international study exploring levels of postpartum depressive symptomatology. Journal of Psychosomatic Research, 49, 207-216. http://dx.doi.org/10.1016/S0022-3999(00)00176-8.

[2] Agostini F, Monti F, Marano G \& Lupi F (2005) L'Edinburgh Postnatal Depression Scale (EPDS) a 3, 9, 18 mesi dopo il parto. Psychofrenia VIII, 12. DOI: 10.1285/117201632vVIIIn12p63.

[3] Banti S, Mauri M, Oppo A, Borri C, Rambelli C, Ramacciotti D, Montagnani MS, Camilleri V, Cortopassi S, Rucci P \& Cassano G (2011) From the third month of pregnancy to 1 year postpartum. Prevalence, incidence, recurrence, and new onset of depression. Results from the Perinatal Depression-Research \& Screening Unit study. Comprehensive Psychiatry, 52, 343-351. http://dx.doi.org/10.1016/j.comppsych.2010.08.003.

[4] Benvenuti P, Ferrara M, Niccolai C, Valoriani V \& Cox JL (1999) The Edinburgh postnatal depression scale: Validation for an italian sample. Journal of Affective Disorder, 53, 137 - 141. http://dx.doi.org/10.1016/S0165-0327(98)00102-5.

[5] Brugha TS, Wheatley S, Taub NA, Culverwell A, Friedman T, Kirwan P, Jones DR \& Shapiro DA (2000) Pragmatic randomized trial of antenatal intervention to prevent post-natal depression by reducing psychosocial risk factors. Psychological Medicine 30, 1273-1281. https://lra.le.ac.uk/bitstream/2381/63/1/brugha_pragmatic.pdf. http://dx.doi.org/10.1017/S0033291799002937.

[6] Burt VK \& Stein K (2002) Epidemiology of depression throughout the female life cycle. Journal of Clinical Psychiatry, 63 Suppl. 7: 9- 15.

[7] Cooper PJ \& Murray L (1995) The course and recurrence of post-nata depression. British Journal of Psychiatry, 166, 191-195. http://dx.doi.org/10.1192/bjp.166.2.191

[8] Cox J, Holden J \& Sagovsky R (1987) Detection of postnatal depression: Development of the 10-item Edinburgh Postnatal Depression Scale. British Journal of Psychiatry, 150, $782-786$ http://dx.doi.org/10.1192/bjp.150.6.782.

[9] Cox J \& Holden JM (2003) Perinatal Mental Health: A guide to the Edinburgh Postnatal Depression Scale. Gaskell, Glasgow. http://dx.doi.org/10.1007/s00737-008-0028-3.

[10]Danaci AE, Dinc G, Deveci A, Sen FS \& Icelli I (2002) Postnatal depression in Turkey: Epidemiological and cultural aspects. Soc. Psychiatry. Social Psychiatry and Psychiatric Epidemiology 37, 125-9. http://dx.doi.org/10.1007/s001270200004.

[11]Dennis CL (2004) Can we identify mothers at risk for postpartum depression in the immediate postpartum period using the Edinburgh Postnatal Depression Scale? Journal of Affective Disorder 78, 163 169. http://dx.doi.org/10.1111/j.1600-0447.2004.00337.x.

[12]Dennis CL, Janssen PA \& Singer J (2004) Identifying women at-risk for postpartum depression in the immediate postpartum period. Acta $\begin{array}{lll}\text { Psychiatrica } & \text { Scandinavica, } & \text { 338-346. }\end{array}$ http://dx.doi.org/10.1111/j.1600-0447.2004.00337.x.

[13]Dennis CL \& Ross LE (2006) Depressive symptomatology in the immediate postnatal period: Identifying maternal characteristics relat- ed to true-and false-positive screening scores. Canadian Journal of Psychiatry, 51, 265-273.

https://ww1.cpa-apc.org/Publications/Archives/CJP/2006/april/cjpapr-06-dennis-OR.pdf.

[14]Dørheim SK, Bondevik GT, Eberhard-Gran M \& Bjorvatn B (2009) Sleep and Depression in Postpartum Women: A Population-Based Study. Sleep, 32, 847-855. http://www.ncbi.nlm.nih.gov/pmc/articles/PMC2704916/pdf/aasm.32. 7.847.pdf

[15]Edhborg M (2008) Comparisons of different instruments to measure blues and to predict depressive symptoms 2 months postpartum: A study of new mothers and fathers. Scandinavian Journal of Caring Sciences, 22, 186-195. http://dx.doi.org/10.1111/j.1471-6712.2007.00512.x.

[16]Evins G \& Theofrastous J (1997) Postpartum depression: A review of postpartum screening. Primary Care Update for Ob/Gyns, 4, $241-$ 245. http://dx.doi.org/10.1016/S1068-607X(97)00105-4.

[17] Gameiro S, Moura-Ramos M \& Canavarro MC (2009) maternal adjustment to the birth of a child: Primiparity versus multiparity. Journal of Reproductive and Infant Psychology, 27, 269 - 286. http://dx.doi.org/10.1080/02646830802350898.

[18] Giakoumaki O, Vasilaki K, Lili L, Skouroliakou M \& Liosis G (2009) The role of maternal anxiety in the early postpartum period: Screening for anxiety and depressive symptomatology in Greece. Journal of Psychosomatic Obstetrics \& Gynecology, 30, 21-28. http://dx.doi.org/10.1080/01674820802604839.

[19] Giardinelli L, Innocenti A, Benni L, Stefanini MC, Lino G, Lunardi C, Svelto V, Sfshar S, Bovani R \& Castellini G (2011) Depression and anxiety in perinatal period: Prevalence and risk factors in an Italian Sample. Archive of Women Mental Health, 15, 21-30. http://dx.doi.org/10.1007/s00737-011-0249-8.

[20]Grussu P, Nasta MT, Quatraro RM, Sichel M \& Cerutti R (2001) La salute psicologica del $1^{\circ}$ anno dopo il parto: Studio longitudinale su un campione di donne primipare. Giornale Italiano di Psicologia, 28 133-135. DOI: $10.1421 / 334$.

[21]Grussu P \& Quatraro RM (2009) Prevalence and risk factors for a high level of postnatal depression symptomatology in Italian women: A sample drawn from ante-natal classes. European Psychiatry, 24, 327 - 333. http://dx.doi.org/10.1016/j.eurpsy.2009.01.006.

[22]Hannah P, Adams D \& Lee A, Glover V \& Sandler M (1992) Links between early post-partum mood and post-natal depression. British Journal of Psychiatry 160, 777 - 780. http://dx.doi.org/10.1192/bjp.160.6.777.

[23]Hung CH (2004) Predictors of postpartum women's health status. Journal of Nursing Scholarship, 36, 345-351. http://dx.doi.org/10.1016/S1976-1317(08)60016-X.

[24]Jardri R, Pelta J, Maron M, Thomas P, Delion P, Codaccioni X \& Goudemand M (2006) Predictive validation study of the Edinburgh Postnatal Depression Scale in the first week after delivery and risk analysis for postnatal depression. Journal of Affective Disorder, 93 , 169 - 176. http://dx.doi.org/10.1016/j.jad.2006.03.009

[25]Leahy-Warren P, McCarthty G \& Corcoran P (2011) Postnatal depression in first time mothers: Prevalence and relationships between functional and structural social support at 6 a 12 weeks postpartum. Ar-

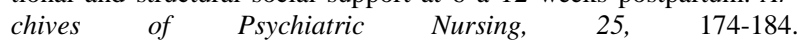
http://dx.doi.org/10.1016/j.apnu.2010.08.005.

[26]Lilja G, Edhborg ME \& Nissen E (2012) Depressive mood in women at childbirth predicts their mood and relationship with infant and partner during the first year postpartum. Scandinavian Journal of Caring Sciences, 26, 245-253. http://dx.doi.org/10.1111/j.1471-6712.2011.00925.x.

[27] MacMahon C, Barnett B, Kowalenko N \& Tennant C (2005) Psychological factors associated with persistent postnatal depression: Past and current relationships, defence styles and the mediating role of insecure attachment style. Journal of Affective Disorder, 84, 15 -24. http://dx.doi.org/10.1016/j.jad.2004.05.005.

[28]Monti F \& Agostini F (2006) La depressione postnatale. Carocci, Roma.

[29]Monti F, Agostini F \& Marano G (2006) Depressione post-partum e interazioni madre- bambino a 3 mesi dopo il parto. Psicologia clinica dello sviluppo. Il Mulino, Bologna.

[30]Murray L \& Carothers AD (1990) The validation of the Edinburgh Post-natal Depression Scale on a community sample. British Journal of Psychiatry, 157, 288-290. http://dx.doi.org/10.1192/bjp.157.2.288.

[31] Nonacs R \& Cohen LS (1998) postpartum mood disorders: Diagnosis and treatment guidelines. Journal of Clinical Psychiatry, 59, 34-40.

[32]Robertson E, Grace S, Wallington T \& Stewaert DE (2004) Antenatal risk factors for post-partum depression: A synthesis of recent literature. Geneneral Hospital Psychiatry, 26, 289-295. http://dx.doi.org/10.1016/j.genhosppsych.2004.02.006. 
[33]Skari H, Skreden M, Malt UF, Dalholt M, Ostensen AB, Egeland T \& Emblem R (2002) Comparative levels of psychological distress, stress symptoms, depression and anxiety after childbirth-a prospective population-based study of mothers and fathers. BJOG: An International Journal of Obstetrics and Gynaecology, 109, 1154-1163. http://dx.doi.org/10.1111/j.1471-0528.2002.00468.x.

[34]Stern DN (1985) The interpersonal world of the infant. Basic Books, New York.

[35] Stocky a \& Lynch J (2000) Acute psychiatric disturbance in pregnancy and puerperium. Baillière's Clinical Obstetrics and Gynaecology, 14, 37 - 87. http://dx.doi.org/10.1053/beog.1999.0064.

[36] Teissedre F \& Chabrol H (2004) Detecting women at risk for postnatal depression using the EPDS at 2 to 3 days postpartum. Canadian Journal of Psychiatry, 49, 51 - 54. http://ww1.cpaapc.org/Publications/Archives/CJP/2004/January/teissedre.pdf

[37]Trevarthen C \& Aitken KJ (2001) Infant intersubjectivity: Research, theory, and clinical applications. Journal of Child Psychology and Psychiatry, 42, 3-48. http://dx.doi.org/10.1111/1469-7610.00701. 